\title{
Communication
}

\section{The Sonic Resonance Method and the Impulse Excitation Technique: A Comparison Study}

\author{
Tomáš Húlan ${ }^{1}$, Filip Obert ${ }^{1}$, Ján Ondruška ${ }^{1}$, Igor Štubňa ${ }^{1}$ and Anton Trník ${ }^{1,2, * \mathbb{C}}$ \\ 1 Department of Physics, Faculty of Natural Sciences, Constantine the Philosopher University in Nitra, \\ Tr. A. Hlinku 1, 94974 Nitra, Slovakia; thulan@ukf.sk (T.H.); filip.obert@ukf.sk (F.O.); jondruska@ukf.sk (J.O.); \\ istubna@ukf.sk (I.Š.) \\ 2 Department of Materials Engineering and Chemistry, Faculty of Civil Engineering, Czech Technical \\ University in Prague, Thákurova 7, 16629 Prague, Czech Republic \\ * Correspondence: atrnik@ukf.sk; Tel.: +421-37-6408-616
}

Citation: Húlan, T.; Obert, F.; Ondruška, J.; Štubňa, I.; Trník, A. The Sonic Resonance Method and the Impulse Excitation Technique: A Comparison Study. Appl. Sci. 2021, 11, 10802. https://doi.org/10.3390/ app112210802

Academic Editors: Jerzy Hoła and Łukasz Sadowski

Received: 19 October 2021

Accepted: 14 November 2021

Published: 16 November 2021

Publisher's Note: MDPI stays neutral with regard to jurisdictional claims in published maps and institutional affiliations.

Copyright: (c) 2021 by the authors. Licensee MDPI, Basel, Switzerland. This article is an open access article distributed under the terms and conditions of the Creative Commons Attribution (CC BY) license (https:/ / creativecommons.org/licenses/by/ $4.0 /)$.

\begin{abstract}
In this study, resonant frequencies of flexurally vibrating samples were measured using the sonic resonant method (SRM) and the impulse excitation technique (IET) to assess the equivalency of these two methods. Samples were made from different materials and with two shapes (prism with rectangular cross-section and cylinder with circular cross-section). The mean values and standard deviations of the resonant frequencies were compared using the $t$-test and the F-test. The tests showed an equivalency of both methods in measuring resonant frequency. The differences between the values measured using SRM and IET were not significant. Graphically, the relationship between the resonant frequencies is a line with a slope of $0.9993 \approx 1$.
\end{abstract}

Keywords: sonic resonant method; impulse excitation technique; resonant frequency

\section{Introduction}

Young's modulus is a mechanical quantity of great importance for solid materials. It depends on different external influences, in addition to the intrinsic properties of the measured material. Therefore, Young's modulus allows an indirect study of, for example, the microstructure (porosity, texture) and the influences of some technological steps (drying or sintering) on ceramic materials. Young's modulus is also a necessary quantity in some engineering calculations, e.g., in the determination of the critical rate of heating a ceramic body.

The most commonly used methods for determining Young's modulus of metals, ceramics, concrete, glass, composites, and biological materials are dynamical methods. Thomaz et al. [1] studied Young's modulus of concrete containing basaltic aggregates using static and dynamic methods, such as the ultrasonic pulse velocity (UPV) and impulse excitation technique (IET). They found out that the dynamic Young's moduli had higher values than the static moduli by approximately $16 \%$ for IET and $28 \%$ for UPV. Using IET, Quaglio et al. [2] determined Young's modulus of samples from basalt and diabase mines used as aggregates in the construction industry. Their results showed that values of Young's modulus had high repeatability and agreed with those reported in the literature for the same material. Using IET, Guicciardi et al. [3] studied the dynamic Young's modulus of $\mathrm{ZrB}_{2}$ based composites containing $\mathrm{MoSi}_{2}$ as a secondary phase up to $1430^{\circ} \mathrm{C}$. Duan et al. [4] used IET to compare the microstructures of several glasses by measuring Young's modulus and the internal friction as a function of temperature. Wang et al. [5] investigated the validity of using the frequency and decay rate of free-free beam vibrations, which were measured by IET, to characterize the viscoelastic properties of glass in the temperature range of glass transition. Ligoda-Chmiel et al. [6] used a traditional compression test and the ultrasonic and impulse excitation of vibration methods to compare and analyze Young's modulus, Kirchoff's modulus, and Poisson's ratio using alumina foam/tri-functional epoxy 
resin composites with an interpenetrating network structure. Radovic et al. [7] compared four different experimental techniques, namely, resonant ultrasound spectroscopy (RUS), impulse excitation, nanoindentation, and the four-point bending test to determine Young's and shear moduli of $99.9 \%$ pure $\mathrm{Al}_{2} \mathrm{O}_{3}, 7075$ aluminum, 4140 steel, and Pyrex glass. They found that dynamic methods (RUS and IET) have superior precision and repeatability, and the differences between the results of RUS and IET were not statistically significant. Haines et al. [8] compared the results from a resonance flexure method and from four-point static flexure tests for wood samples.

Dynamical methods based on measurement of the resonant frequency of a vibrating sample are relatively simple and produce very low mechanical stress that does not initiate inelastic processes in tested material. Under such a low stress, the assumptions of the elastic theory of vibration are well fulfilled. Another advantage of these methods is their applicability for high temperature measurements $[9,10]$. If resonant frequency is measured in a defined temperature regime, e.g., during heating/cooling with a constant rate, such measurement falls under thermal analysis and is called dynamical thermomechanical analysis (D-TMA).

A rectangular prism or a rod with a circular cross-section, both having free ends, are commonly used for determination of Young's modulus. The longitudinal vibration or flexural vibration of such samples are possible for measurement purposes, but the flexural vibration is preferable because it can be easily excited, gives more intense amplitude, and the resonant frequency is lower compared to the longitudinal vibration. Two kinds of vibrations are used [11,12]:

(a) Driven vibrations with a known frequency. The driven vibrations are the base of the sonic resonance method (SRM).

(b) Free vibrations excited by the mechanical impulse. The free vibrations are the base of the impulse excitation technique (IET).

Historically, the first technique was SRM [10,12]. The equipment used consists of a tunable oscillator with an amplifier connected to an exciter as the source of driven vibrations. The sample is suspended in its nodal points, vibrations are registered using a sensor connected to a preamplifier, and the sensor's output signal is observed. The frequency at which the output signal reaches the maximum value is the resonant frequency. This method can be automated, for example, if the RC oscillator works in a sweeping regime $[13,14]$ or the sample is permanently kept in the resonant vibration with the help of a voltage-controlled oscillator in a feedback loop which contains the sensor [15].

Roebben et al. [16] presented an apparatus to measure elastic properties and the internal friction of materials. Their apparatus excited the sample fixed in the nodal points of the fundamental vibration mode via a light mechanical impact. The response includes many transient frequencies that rapidly die out, and thus there is a natural filtering action leaving the main fundamental resonant vibrations as the only detected signal. Then the apparatus performed a software-based analysis of the resulting vibration, i.e., IET was used. The resonant frequency of the sample was determined and Young's modulus was calculated. Similar techniques were also described in [11,17-20]. The sample vibration is captured by a microphone or a piezo electrical sensor and subsequently analyzed using the fast Fourier transformation (FFT). The result of the FFT is a frequency spectrum of the sample vibrations, where the resonant frequency of the fundamental mode of the vibrations can be found. Another way to extract the resonant frequency from the measured signal is based on measurement of the duration of a selected number of cycles by counting zero-crossings and determining the cycle period. Its duration is directly proportional to the reciprocal value of the resonant frequency.

The free vibrations are naturally suppressed by internal processes in the sample. Therefore, a coefficient of the internal damping (internal friction) can be determined. The mechanical impulse can be realized manually with a hammer if the measurement is conducted at room temperature. The impulse can be generated at an elevated temperature by steel or ceramic balls which fall on the sample, and by an electromagnetic impactor. 
In high-temperature measurements, IET can be designed as non-contact, whereas SRM needs two thin wire suspensions located at the antinodal points or at the ends of the sample. These suspensions are a drawback of SRM — they are often the source of spurious resonances, and their strength is limited at high temperatures. Consequently, IET is more reliable at high temperatures.

Both methods, SRM and IET, have the same theoretical basis, which is an equation of the flexural vibration of the rectangular beam or rod with a circular cross-section, and their material is homogenous and isotropic [10,21]. A derivation of the equation of the flexural vibration can be found, for example, in [9,10,21-23]. The relationship for Young's modulus $E$ derived from this simplified equation has a form:

$$
E=\left(K \frac{l^{2} f_{0}}{d}\right)^{2} \rho T,
$$

where $f_{0}$ is the resonant frequency of the fundamental mode, $\rho$ is the material bulk density, $l$ is the length of the sample, and $d$ is the diameter of the cylindrical sample or thickness of the prismatic sample in the direction of vibration. If $l / d>20$, the correction coefficient $T=1$. If $l / d<20$, the influence of rotary inertia and shear forces have to be taken into account to obtain correct values of Young's modulus. Two ways are possible: (1) The use of the very complex frequency equation for the so-called Timoshenko beam. When the measured frequency is substituted in this equation, Young's modulus can be calculated using a numerical method. (2) The use of the simplified equation for a slender beam from which the frequency equation and Equation (1) with $T=1$ can be derived. The correction coefficient $T>1$ should be used for cases $l / d<20$. The value of $T$ can be calculated from formulae given in [11,12] or can be found in tables in [10]. This second way is commonly used in experimental practice and is described in standards, e.g., ASTM [11,12].

The values of the constant $K$ are:

$K=1.12336$ for a cylindrical sample and the fundamental resonant frequency;

$K=0.97286$ for a prismatic sample and the fundamental resonant frequency.

Theoretically, IET and SRM should give the same resonant frequency for the given sample. The authors have found only one short technical note [24] which confirms this equality on the basis of experimental results obtained on a concrete prism.

The aim of this article is to compare the resonant frequencies of the flexurally vibrating free-free beam measured by IET and SRM on different samples. This frequency can be substituted into a formula for the calculation of Young's modulus (together with dimensions and mass of the sample). When the same sample is used for SRM and IET, the difference of resonant frequencies can be only observed, because the shape, dimensions, and intrinsic properties of the sample, in addition to the boundary conditions (free-free sample), are the same for SRM and IET.

\section{Materials and Methods}

\subsection{Samples}

The measured samples were made from metal, ceramics, and glass. Their material, dimensions, and shape (prism or cylinder) are given in Table 1. Every sample was measured 12 times by SRM and IET. 
Table 1. Used materials for the measurements by SRM and IET method.

\begin{tabular}{|c|c|c|}
\hline No. & Sample Material & Sample Dimensions $[\mathrm{mm}]$ \\
\hline 1 & Aluminum & $\varnothing 12 \times 110$ (cylinder) \\
\hline 2 & Stainless steel & $\varnothing 8 \times 110$ (cylinder) \\
\hline 3 & Carbon steel & $8.5 \times 8.2 \times 163($ prism $)$ \\
\hline 4 & Kaolin ceramics $^{1}$ & $\varnothing 12 \times 110$ (cylinder) \\
\hline 5 & Kaolin ceramics $^{2}$ & $\varnothing 15 \times 110$ (cylinder) \\
\hline 6 & Alumina porcelain & $10 \times 11 \times 110($ prism $)$ \\
\hline 7 & Soda-lime glass & $\varnothing 8 \times 145$ (cylinder) \\
\hline 8 & Corundum ceramics & $\varnothing 8 \times 175$ (cylinder) \\
\hline 9 & Silicon carbide & $\varnothing 14 \times 150$ (cylinder) \\
\hline
\end{tabular}

\subsection{Measurement Methods}

Two methods were used for this comparison: the sonic resonant method (SRM) and the impulse excitation technique (IET). The sample was placed horizontally on a narrow soft foam pads at a distance $0.224 l$ from the sample ends, where the nodal points are located.

The SRM apparatus was as follows (Figure 1): the exciter (speaker Tesla ARZ 098, $75 \Omega, 0.15 \mathrm{~W}$, frequency range of $300-6000 \mathrm{~Hz}$ ) was located under the center of the sample. The speaker was fed by a sinusoidal voltage from a PC-controlled oscillator M631 (ETC Žilina, Slovakia) which worked in the sweeping regime. The oscillator changed the frequency by $1 \mathrm{~Hz}$ steps with $20 \mathrm{~ms}$ dwelling on each step. The sensor was placed on the end of the sample. The sensor was a piezoelectric gramophone cartridge that affected the sample via a very small force with the help of a lever with a counterweight. The output of the sensor was connected to a preamplifier and PC. If the sensor was moved around the nodal point, the output signal, which was visible in the PC monitor, reached the minimum value in the nodal point. This technique helps to confirm a fundamental mode of the flexural vibrations.

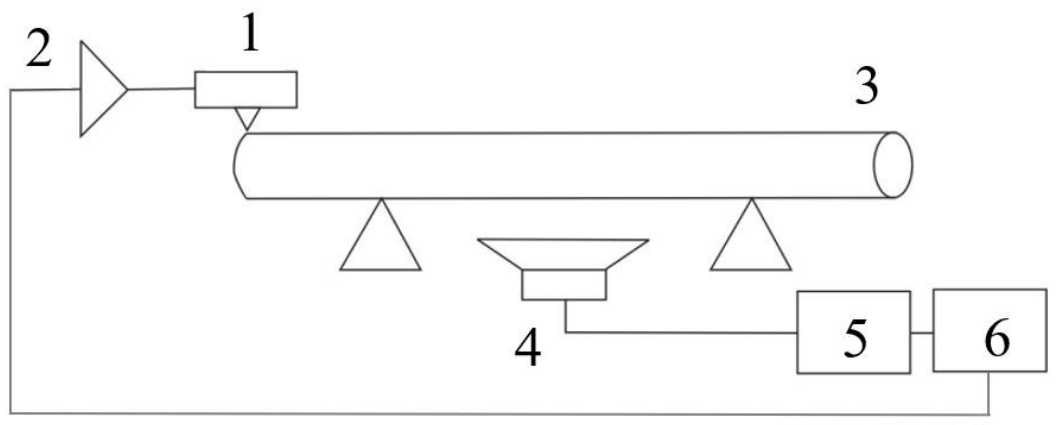

Figure 1. SRM apparatus (1-sensor, 2-preamplifier, 3-sample, 4-exciter, 5-oscillator, 6-personal computer).

The IET apparatus was as follows (Figure 2): The vibrations of the sample were excited by the hit of a small hammer (steel ball glued to a thin wooden stick). The sound was caught by an electric microphone connected to a low-frequency preamplifier and PC, in which the signal was changed into a frequency spectrum using fast Fourier transformation. The sampling frequency was $40 \mathrm{kHz}$ and the period of recording the free vibrations after mechanical impact was $1 \mathrm{~s}$. The resonant frequency was able to be determined with a resolution of $1.221 \mathrm{~Hz}$. 


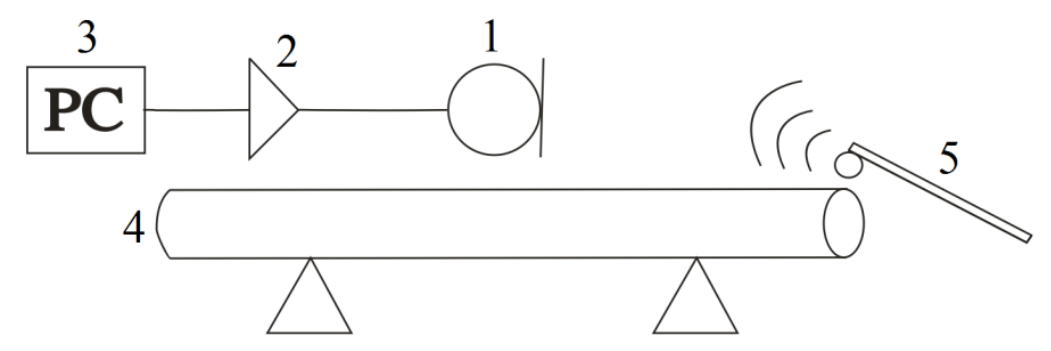

Figure 2. IET apparatus (1-microphone, 2-preamplifier, 3-personal computer, 4-sample, 5 -hammer).

The measured sample was placed horizontally on two supports in the nodal points ( $0.224 l$ from the both ends) for both the SRM and IET experiments.

\section{Results}

Because the material, dimensions, mass, and intrinsic properties of the sample were the same for both methods, SRM and IET, only resonant frequencies obtained by SRM and IET could be different. Therefore, only these frequencies were taken into account for the comparison of SRM and IET.

The results obtained by the SRM and IET are shown in Table 2. The resonant frequency of each sample (listed in Table 1) was measured 12 times with both methods and the mean values and standard deviations were calculated. The relative differences between the mean values of the resonant frequencies $f_{I E T}$ and $f_{S R M}$, were calculated according to the equation:

$$
\frac{\Delta f}{f_{m}}=\frac{2\left(f_{S R M}-f_{I E T}\right)}{f_{S R M}+f_{I E T}} .
$$

Table 2. Resonant frequency measured using SRM and IET method.

\begin{tabular}{|c|c|c|c|c|c|c|c|}
\hline No. & $\begin{array}{l}\text { Sample } \\
\text { Material }\end{array}$ & Method & $\begin{array}{c}\text { Resonant } \\
\text { Frequency }[\mathrm{Hz}]\end{array}$ & $\begin{array}{c}\text { Standard } \\
\text { Deviation }[\mathrm{Hz}]\end{array}$ & $\begin{array}{l}\text { Relative Difference } \\
\qquad \Delta f / f_{m}\end{array}$ & $t$-Test Score & F-Test Score \\
\hline \multirow{2}{*}{1} & \multirow{2}{*}{ Aluminum } & SRM & 4381.75 & 3.7444 & \multirow{2}{*}{-0.00029} & \multirow{2}{*}{0.88} & \multirow{2}{*}{1.38} \\
\hline & & IET & 4383.00 & 3.1856 & & & \\
\hline \multirow{2}{*}{2} & \multirow{2}{*}{ Stainless steel } & SRM & 3068.05 & 2.3448 & \multirow{2}{*}{-0.00003} & \multirow{2}{*}{0.10} & \multirow{2}{*}{1.19} \\
\hline & & IET & 3068.15 & 2.5589 & & & \\
\hline \multirow{2}{*}{3} & \multirow{2}{*}{ Carbon steel } & SRM & 1553.85 & 35.0418 & \multirow{2}{*}{0.00158} & \multirow{2}{*}{0.16} & \multirow{2}{*}{1.32} \\
\hline & & IET & 1551.39 & 40.2075 & & & \\
\hline \multirow{2}{*}{4} & \multirow{2}{*}{$\begin{array}{c}\text { Kaolin } \\
\text { ceramics }\end{array}$} & SRM & 3374.54 & 82.9955 & \multirow{2}{*}{0.00562} & \multirow{2}{*}{0.53} & \multirow{2}{*}{1.22} \\
\hline & & IET & 3355.64 & 91.7184 & & & \\
\hline \multirow{2}{*}{5} & \multirow{2}{*}{$\begin{array}{c}\text { Kaolin } \\
\text { ceramics }^{2}\end{array}$} & SRM & 3421.60 & 10.6667 & \multirow{2}{*}{-0.00050} & \multirow{2}{*}{0.38} & \multirow{2}{*}{1.16} \\
\hline & & IET & 3423.31 & 11.4891 & & & \\
\hline \multirow{2}{*}{6} & \multirow{2}{*}{$\begin{array}{l}\text { Alumina } \\
\text { porcelain }\end{array}$} & SRM & 2952.85 & 144.0841 & \multirow{2}{*}{-0.00023} & \multirow{2}{*}{0.01} & \multirow{2}{*}{1.03} \\
\hline & & IET & 2953.52 & 141.7116 & & & \\
\hline \multirow{2}{*}{7} & \multirow{2}{*}{$\begin{array}{l}\text { Soda-lime } \\
\text { glass }\end{array}$} & SRM & 2372.19 & 9.3747 & \multirow{2}{*}{-0.00011} & \multirow{2}{*}{0.06} & \multirow{2}{*}{1.22} \\
\hline & & IET & 2372.45 & 10.3524 & & & \\
\hline \multirow{2}{*}{8} & Corundum & SRM & 1813.70 & 4.2823 & 0.00006 & 0.06 & 1.10 \\
\hline & ceramics & IET & 1813.59 & 4.4912 & & & \\
\hline 0 & Cilison & SRM & 2932.75 & 3.9341 & 000050 & 105 & 191 \\
\hline 3 & Sillcon cardide & IET & 2931.28 & 2.8493 & & & \\
\hline
\end{tabular}

\footnotetext{
${ }^{1}$ Ceramics based on Sedlec kaolin fired at $1150{ }^{\circ} \mathrm{C} .{ }^{2}$ Ceramics based on Kemmlitz kaolin fired at $1150{ }^{\circ} \mathrm{C}$.
} 
Table 2 shows that this difference is low, mostly less than $0.05 \%$, and the highest value of $0.56 \%$ was valid for kaolin ceramics. These small differences suggest good agreement between IET and SRM results.

To obtain more reliable information, a t-test (see e.g., $[25,26])$ was performed to compare mean values. The number of samples was $n_{S R M}=n_{I E T}=n=12$. The degrees of freedom $k=n_{S R M}+n_{I E T}-2=22$ and the critical test score $t_{\text {crit }}=2.07$ for the significance level $\alpha=0.05$ were the same for every comparison. The test scores $t$ for different samples were calculated according to the equation

$$
t=\left|f_{I E T}-f_{S R M}\right| \sqrt{\frac{n}{s_{I E T}^{2}+s_{S R M}^{2}}},
$$

where $s_{I E T}$ and $s_{S R M}$ are the standard deviations.

Because all $t$-test scores $<t_{\text {crit }}=2.07$, the mean values obtained by SRM and IET can be considered as equivalent. The differences between the measurement results can be considered in the scope of the measurement errors.

To compare the deviations of measured data, Fisher's test was employed $[25,26]$. The F-test score was calculated for degrees of freedom $k_{S R M}=n_{S R M}-1=11$ and $k_{I E T}=$ $n_{I E T}-1=11$ for the significance level $\alpha / 2=0.025$, for which $F_{\text {crit }}=3.47$. The F-test score was calculated according to the formula:

$$
F=\frac{s_{1}^{2}}{s_{2}^{2}}
$$

where $s_{1}$ and $s_{2}$ are standard deviations ( $s_{I E T}$ and $\left.s_{S R M}\right)$ and $s_{1}>s_{2}$, therefore $F>1$. The F-test scores (see Table 2 ) were $<F_{\text {crit }}=3.47$; therefore, it can be considered that standard deviations of SRM and IET are very close to each other. Consequently, both methods are equivalent for measuring the resonant frequency.

The comparative tests confirmed that SRM and IET are equivalent methods that give identical values of the resonant frequency. This is also shown graphically in Figure 3 . The relationship between resonant frequencies measured by SRM and IET for different samples must be presented by the line with a slope $=1$. As can be seen, the experimental points are lying on the line with a slope $0.9993 \approx 1$, which confirms the equivalence of the SRM and IET methods. The data for samples 6 and 9 are very close to each other and merge to one point in the graph.

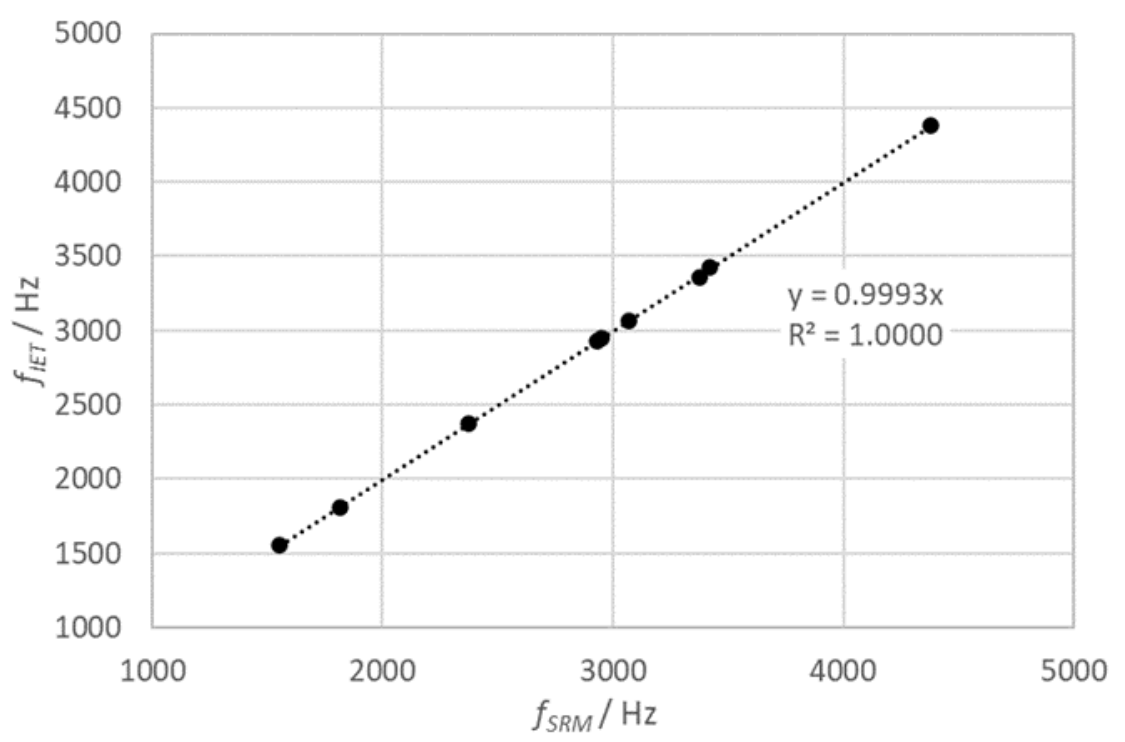

Figure 3. Dependence of resonant frequencies for samples measured by IET and SRM. 
Young's moduli calculated from measured resonant frequencies (by SRM and IET) for the tested samples (Table 2) are given in Table 3, where they are compared to Young's moduli for similar materials from the literature. It can be seen that Young's moduli obtained by SRM and IET are close to each other, and also are in good agreement with already published results. The differences are mainly caused by different porosity and chemical composition.

Table 3. Young's modulus of used materials determined by SRM and IET methods, and Young's modulus from the literature.

\begin{tabular}{ccccc}
\hline No. & Sample Material & $E$ [GPa] (SRM) & $E$ [GPa] (IET) & $E$ [GPa] (Ref.) \\
\hline 1 & Aluminum & 73.61 & 73.65 & $70[27]$ \\
\hline 2 & Stainless steel & 212.31 & 212.32 & $168-206[28]$ \\
\hline 3 & Carbon steel & 226.64 & 225.92 & $207[29]$ \\
\hline 4 & Kaolin ceramics $^{1}$ & 30.27 & 29.93 & $29[30]$ \\
\hline 5 & Kaolin ceramics $^{2}$ & 20.57 & 20.59 & $29[30]$ \\
\hline 6 & Alumina porcelain & 56.60 & 56.62 & $55-85[31,32]$ \\
\hline 7 & Soda-lime glass & 70.06 & 70.07 & 73 [33] \\
\hline 8 & Corundum ceramics & 246.75 & 246.72 & $154-377[34]$ \\
\hline 9 & Silicon carbide & 94.00 & 93.91 & $100-400[35]$ \\
\hline
\end{tabular}

${ }^{1}$ Ceramics based on Sedlec kaolin fired at $1150{ }^{\circ} \mathrm{C} .{ }^{2}$ Ceramics based on Kemmlitz kaolin fired at $1150{ }^{\circ} \mathrm{C}$.

\section{Conclusions}

Samples made from different materials (metal, ceramics, and glass) and with two shapes (a prism with a rectangular cross-section and a cylinder with a circular crosssection) were examined using the sonic resonant method (SRM) and impulse excitation technique (IET) to confirm the equality of the two methods for measuring the resonant frequency $f$ of flexurally vibrating samples. The mean values of the resonant frequencies and standard deviations were compared using the t-test and the F-test. The tests showed that both methods produced the same values of the resonant frequency. Small differences were within the scope of measurement error. This was also confirmed using the graph of the function $f_{I E T}\left(f_{S R M}\right)$, which was a line with the slope of $0.9993 \approx 1$. Young's moduli calculated for the tested samples were compared with those published in the literature and good agreement was found.

Author Contributions: Conceptualization, I.Š.; methodology, T.H., I.Š. and A.T.; investigation, T.H., F.O., J.O. and A.T.; writing — original draft preparation, I.Š., T.H. and A.T.; writing—review and editing, T.H., F.O., J.O., I.S. and A.T.; visualization, A.T.; supervision, I.Š. and A.T.; project administration, A.T.; funding acquisition, A.T. All authors have read and agreed to the published version of the manuscript.

Funding: This research was funded by Ministry of Education of Slovak Republic, grant number KEGA 027UKF-4/2019 and by RVO: 11000.

Institutional Review Board Statement: Not applicable.

Informed Consent Statement: Not applicable.

Conflicts of Interest: The authors declare no conflict of interest. The funders had no role in the design of the study; in the collection, analyses, or interpretation of data; in the writing of the manuscript, or in the decision to publish the results. 


\section{References}

1. Thomaz, W.D.; Miyaji, D.Y.; Possan, E. Comparative study of dynamic and static Young's modulus of concrete containing basaltic aggregates. Case Stud. Constr. Mater. 2021, 15, e00645. [CrossRef]

2. Quaglio, O.A.; da Silva, J.M.; Rodovalho, E.D.; Costa, L.D. Determination of Young's modulus by specific vibration of basalt and diabase. Adv. Mater. Sci. Eng. 2020, 2020, 4706384. [CrossRef]

3. Guicciardi, S.; Swarnakar, A.K.; Van der Biest, O.; Sciti, D. Temperature dependence of the dynamic Young's modulus of ZrB2-MoSi2 ultra-refractory ceramic composites. Scr. Mater. 2010, 62, 831-834. [CrossRef]

4. Duan, R.G.; Roebben, G.; Van der Biest, O. Glass microstructure evaluations using high temperature mechanical spectroscopy measurements. J. Non-Cryst. Solids 2003, 316, 138-145. [CrossRef]

5. Wang, J.B.; Ruan, H.H.; Wang, X.; Wan, J.Q. Investigating relaxation of glassy materials based on natural vibration of beam: A comparative study of borosilicate and chalcogenide glasses. J. Non-Cryst. Solids 2018, 500, 181-190. [CrossRef]

6. Ligoda-Chmiel, J.; Potoczek, M.; Sliwa, R.E. Mechanical properties of alumina foam/tri-functional epoxy resin composites with an interpenetrating network structure. Arch. Metall. Mater. 2015, 60, 2757-2762. [CrossRef]

7. Radovic, M.; Lara-Curzio, E.; Riester, L. Comparison of different experimental techniques for determination of elastic properties of solids. Mater. Sci. Eng. A-Struct. Mater. Prop. Microstruct. Process. 2004, 368, 56-70. [CrossRef]

8. Haines, D.W.; Leban, J.M.; Herbe, C. Determination of Young's modulus for spruce, fir and isotropic materials by the resonance flexure method with comparisons to static flexure and other dynamic methods. Wood Sci. Technol. 1996, 30, 253-263. [CrossRef]

9. Kashtaljan, J.A. Elastic Characteristics of Materials at High Temperatures; Naukova Dumka: Kiev, Ukraine, 1970. (In Russian)

10. Schreiber, E.; Anderson, O.; Soga, N. Elastic Constants and Their Measurement; McGraw-Hill Book Co.: New York, NY, USA, 1974.

11. ASTM C 1259-15. Standard Test Method for Dynamic Young's Modulus, Shear Modulus and Poisson's Ratio for Advanced Ceramics by Impulse Excitation of Vibration; ASTM International: West Conshohocken, PA, USA, 2015.

12. ASTM E1875-13. Standard Test Method for Dynamic Young's Modulus, Shear Modulus, and Poisson's Ratio by Sonic Resonance; ASTM International: West Conshohocken, PA, USA, 2013.

13. Štubňa, I.; Trník, A.; Vozár, L. Determination of Young's modulus of ceramics from flexural vibration at elevated temperatures. Acta Acust. United Acust. 2011, 97, 1-7. [CrossRef]

14. Lins, W.; Kaindl, G.; Peterlik, H.; Kromp, K. A novel resonant beam technique to determine the elastic moduli in dependence on orientation and temperature up to $2000^{\circ} \mathrm{C}$. Rev. Sci. Instrum. 1999, 70, 3052-3058. [CrossRef]

15. Landers, H.; Melzer, D.; Klinger, W. A system for measurement of dynamical modulus of elasticity at high temperatures. Silikattechnik 1977, 28, 275-277. (In German)

16. Roebben, G.; Bollen, B.; Brebels, A.; van Humbeeck, J.; van der Biest, O. Impulse excitation apparatus to measure resonant frequencies, elastic moduli and internal friction at room and high temperature. Rev. Sci. Instrum. 1997, 68, 4511-4515. [CrossRef]

17. Štubňa, I.; Húlan, T.; Trník, A.; Vozár, L. Uncertainty in the determination of Young's modulus of ceramics using the impulse excitation technique at elevated temperatures. Acta Acust. United Acust. 2018, 104, 269-276. [CrossRef]

18. Sakata, M.; Kimura, K.; Mizunuma, A. Measurement of elastic moduli from the impact sound of engineering ceramics and composites at elevated temperatures. J. Am. Ceram. Soc. 1995, 78, 3040-3044. [CrossRef]

19. Miloserdin, J.V.; Baranov, V.M. High-Temperature Testing of Reactor Materials; Atomizdat: Moskva, Russia, 1978. (In Russian)

20. Heritage, K.; Frisby, C.; Wolfenden, A. Impulse excitation technique for dynamic flexural measurements at moderate temperature. Rev. Sci. Instrum. 1988, 59, 973-974. [CrossRef]

21. Štubňa, I.; Trník, A. Equations for the flexural vibration of a sample with a uniform cross-section. Strojniski Vestn.-J. Mech. Eng. 2005, 51, 90-94.

22. Bosomworth, P.A. Improved frequency equations for calculating the Young's modulus of bars of rectangular or circular cross section from their flexural resonant frequencies. J. ASTM Int. 2011, 7, 1-14. [CrossRef]

23. Štubňa, I.; Majerník, V. An alternative equation of the flexural vibration. Acustica 1998, 84, 999-1001.

24. Chu, W.T. A comparison of two test methods for measuring Young's modulus of building materials. Can. Acoust. 1996, $24,11$.

25. Dowdy, S.; Wearden, S. Statistics for Research; John Willey \& Sons: New York, NY, USA, 1983.

26. Linczényi, A. Engineering Statistics; Alfa: Bratislava, Slovakia, 1973. (In Slovak)

27. Yu, Z.Y.; Tan, Z.Q.; Fan, G.L.; Xiong, D.B.; Guo, Q.; Lin, R.B.; Hu, L.; Li, Z.Q.; Zhang, D. Effect of interfacial reaction on Young's modulus in CNT/Al nanocomposite: A quantitative analysis. Mater. Charact. 2018, 137, 84-90. [CrossRef]

28. Zhang, R.Z.; Buchanan, C.; Matilainen, V.P.; Daskalaki-Mountanou, D.; Ben Britton, T.; Piili, H.; Salminen, A.; Gardner, L. Mechanical properties and microstructure of additively manufactured stainless steel with laser welded joints. Mater. Des. 2021, 208, 109921. [CrossRef]

29. Qiu, H.; Ueji, R.; Kimura, Y.; Inoue, T. Grain-to-grain interaction effect in polycrystalline plain low-carbon steel within elastic deformation region. Materials 2021, 14, 1865. [CrossRef]

30. Antal, D.; Húlan, T.; Štubňa, I.; Záleská, M.; Trník, A. The Influence of texture on elastic and thermophysical properties of kaolinand illite-based ceramic bodies. Ceram. Int. 2017, 43, 2730-2736. [CrossRef]

31. Al-Shantir, O.; Trník, A.; Csáki, Š. Influence of firing temperature and compacting pressure on density and Young's modulus of electroporcelain. AIP Conf. Proc. 2018, 1988, 020001. [CrossRef]

32. Štubňa, I.; Šín, P.; Trník, A.; Podoba, R.; Vozár, L. Development of Young's modulus of the green alumina porcelain raw mixture. J. Aust. Ceram. Soc. 2014, 50, 36-42. 
33. Gong, J.H.; Deng, B.; Jiang, D.Y. A universal function for the description of nanoindentation unloading data: Case study on soda-lime glass. J. Non-Cryst. Solids 2020, 544, 120067. [CrossRef]

34. Bogdanov, S.P.; Kozlov, V.V.; Shevchik, A.P.; Dolgin, A.S. Young's modulus of corundum ceramics sintered from powders with a core-shell structure synthesized by iodine transport. Refract. Ind. Ceram. 2019, 60, 405-408. [CrossRef]

35. Pabst, O.; Schiffer, M.; Obermeier, E.; Tekin, T.; Lang, K.D.; Ngo, H.D. Measurement of Young's modulus and residual stress of thin SiC layers for MEMS high temperature applications. Microsyst. Technol. 2012, 18, 945-953. [CrossRef] 